\title{
ANALISIS STRATEGI KEMUDAHAN PELAYANAN DAN AKURASI PPOB TERHADAP KINERJA PAYMENT POINT ONLINE BANKING (PPOB) PADA PELANGGAN PT PERUSAHAAN GAS NEGARA
}

\author{
BUNGA ADITI
}

\author{
Dosen Fakultas ekonomi \\ STIE Harapan Medan
}

\begin{abstract}
ABSTRAK
PT Perusahaan Gas Negara (PGN) semakin memantapkan posisinya sebagai BUMN yang memiliki komitmen dan konsistensi dalam pengembangan insfrakstruktur dan pemanfaatan gas bumi di Indonesia. Hal tersebut dibuktikan oleh PGN melalui sejumlah aksi korporasi dalam bentuk pembangunan sejumlah infrastruktur gas baru dan akuisisi blok migas diberbagai wilayah di Indonesia. Di sektor infrastruktur, selama tahun 2013 PGN telah membangun dan mengoperasikan mobile refueling Unit (MRU) untuk mendukung program konversi gas bumi bagi armada transportasi.Penggunaan gas bumi kini semakin meluas.Gas bumi kini menjadi kebutuhan pokok di hampir setiap rumah tangga. Penggunaannya terutama buat pelanggan sebagai bahan bakar untuk menyalakan kompor guna memasak sehari-hari, pemanas air, genset, dan pendingin ruangan. Sampai saat ini sudah tersedia layanan pendistribusian gas bumi untuk pelanggan Rumah Tangga. Dengan layanan ini pelanggan tidak perlu membeli tabung gas secara rutin seperti yang kita ketahui selama ini. Cukup dengan berlangganan, gas bumi akan dialirkan melalui pipa, langsung kerumah-rumah pelanggan. Selanjutnya pelanggan tinggal membayar tiap bulan sesuai dengan banyaknya pemakaian gas bumi perbulan. Metode dalam penelitian ini dengan pendekatan survey, jenis penelitian ini adalah deskriptif kuantitatif Eksplanatory.Metode pengumpulan data dilakukan dengandaftar pertanyaandan studi dokumentasi. Metode analisis data dengan menggunakan regresi linear berganda. Hasil penelitian menunjukkan Kemudahan pelayanan dan Akurasi PPOB secara bersama-sama berpengaruh positif dan signifikan dalam meningkatkan kinerja PPOB pada pelanggan PT Perusahaan Gas Negara.Kemudahan pelayanan secara parsial berpengaruh positif dan signifikan dalam meningkatkan kinerja PPOB, Akurasi PPOB secara parsial berpengaruh positif dan signifikan dalam meningkatkan kinerja PPOB. Hasil penelitian menunjukkan Akurasi PPOB yang dominan dalam meningkatkan kinerja PPOB pada pelanggan PT Perusahaan Gas Negara.Nilai koefisien determinasi ( $R$ square) menunjukkan bahwa kemampuan. Kemudahan pelayanan dan Akurasi PPOB dapat menjelaskan variasi cukup kuat dalam meningkatkan kinerja PPOB pada pelanggan PT Perusahaan Gas Negara.
\end{abstract}

Kata Kunci : Pelayanan, Akurasi PPOB, Kinerja Payment

\section{PENDAHULUAN}

PT Perusahaan Gas Negara (PGN) semakin memantapkan posisinya sebagai BUMN yang memiliki komitmen dan konsistensi dalam pengembangan insfrakstruktur dan pemanfaatan gas bumi di Indonesia. Hal tersebut dibuktikan oleh PGN melalui sejumlah aksi korporasi dalam bentuk pembangunan sejumlah infrastruktur gas baru dan 
akuisisi blok migas diberbagai wilayah di Indonesia. Di sektor infrastruktur, selama tahun 2013 PGN telah membangun dan mengoperasikan mobile refueling Unit (MRU) untuk mendukung program konversi gas bumi bagi armada transportasi.

Penggunaan gas bumi kini semakin meluas.Gas bumi kini menjadi kebutuhan pokok di hampir setiap rumah tangga. Penggunaannya terutama buat pelanggan sebagai bahan bakar untuk menyalakan kompor guna memasak sehari-hari, pemanas air, bahan bakar genset dan lain lain. Sampai saat ini sudah tersedia layanan pendistribusian gas bumi untuk pelanggan Rumah Tangga.Dengan layanan ini pelanggan tidak perlu membeli tabung gas secara rutin seperti yang kita ketahui selama ini. Cukup dengan berlangganan, gas bumi akan dialirkan melalui pipa, langsung kerumah-rumah pelanggan. Selanjutnya pelanggan tinggal membayar tiap bulan sesuai dengan banyaknya pemakaian gas bumi perbulan.

Jumlah pelanggan yang telah menggunakan gas bumi melalui pipa di Kota Medan mulai dari tahun 2008 sampai dengan tahun 2013 semakin bertambah jumlahnya.Volume gas yang tersalur juga semakin meningkat dari tahun 2008 sampai dengan tahun 2012. Hal ini memberikan gambaran bahwa kebutuhan gas saat ini sangat berpengaruh terhadap kebutuhan pelanggan dalam melakukan aktivitas sehari-hari.

Bertambahnya jumlah pelanggan setiap tahunnya dalam menggunakan gas melalui penyaluran pipa di kota Medan, memberikan manfaat atau keuntungan yang cukup besar buat PT Perusahaan Gas Negara dalam pencapaian tujuan organisasi, namun yang menjadi kendala adalah pada saat pembayaran tagihan rekening gas, dimana perusahaan masih kewalahaan pada saat itu karena jumlah loket pembayaran yang tersedia hanya 1 di kantor PT Perusahaan Gas Negara, letaknya pun jauh dari keberadaan pemukiman sehingga pelanggan merasa sistem pembayaran PT Perusahaan Gas Negara kurang efektif dan pelanggan juga kurang nyaman dalam membayar tagihan rekening gas akibat dari banyaknya antrian yang terjadi pada saat pembayaran rekening gas.

Untuk mempermudah pelayanan pelanggan, PT Perusahaan Gas Negara mengembangkan kinerja Payment Point Online Banking (PPOB) sebagai cara yang sangat mudah, praktis, cepat dalam melakukan pembayaran tagihan. Sistem pembayaran sebelum adanya Payment Point Online Banking (PPOB) masih dilakukan secara manual, sehingga pelanggan datang langsung untuk membayar tagihan gas ke loket yang telah disediakan PT Perusahaan Gas Negara, namun semakin banyaknya keluhan dari pelanggan dan bertambahnya jumlah pelanggan yang mengakibatkan banyak antrian, maka loket yang tersedia tidak sanggup untuk melayanipelangan.

Pada tahun 2011 jumlah pelanggan yang mendaftar sebanyak 3704 rumah tangga (19\%), kemudian pada tahun 2012 turun menjadi 2824 rumah tangga (15\%) dan pada tahun 2013 juga menurun menjadi 2067 rumah tangga (11\%).Adanya penurun pelanggan diakibatkan masih banyak yang harus dibenahi di dalam sistem, salah satu masalah yang terjadi di dalam sistem yaitu identitas pelanggan belum semua masuk di dalam sistem, sistem pembayaran belum semua dapat online di atm Bank.Hal ini menunjukkan investasi besar yang telah dilakukan PT Perusahaan Gas Negara belum memberikan keuntungan terhadap negara, karena banyak pelanggan yang kembali lagi membayar tagihan gas melalui pembayaran langsung. Belum optimalnya kinerja PPOB menjadikan sebuah permasalahaan buat PT Perusahaan Gas Negara dalam memperbaiki dan meningkatkan teknologi yang lebih baik lagi.

PT Perusahaan Gas Negara tidak tinggal diam saja. Perusahaan mensosialisasikan PPOB kepada pelanggan, cara yang dilakukan oleh PT Perusahaan Gas Negara adalah 
bagi pelanggan baru diberikan petunjuk pembayaran tagihan melalui cara online yang dilengkapi dengan buku petunjuk. Bagi pelanggan yang mau beralih ke sistem online dilengkapi berkas untuk mendaftarkan ke sistem online, kemudian setiap pelanggan yang belum mengetahui sistem PPOB maka pegawai mendatangi rumah-rumah pelanggan untuk menyebarkan selebaran tentang penggunaan PPOB dan memberikan informasi dengan akurat cara mudah membayar tagian gas tanpa datang lagi ke kantor pembayaran.

Survei terhadap pelanggan telah dilakukan oleh PT Perusahaan Gas Negara pada Tahun 2011 sampai dengan Tahun 2012 tentang kepuaasan pelanggan dalam menggunakan PPOB menunjukkan dari 100 orang yang disurvey, menyatakan puas terhadap pelayanan PPOB sebanyak 60 orang sedangkan yang tidak puas sebanyak 40 orang yang kemudian pelanggan kembali lagi beralih membayar secara manual dengan datang langsung ke kantor pembayaran. Pada Tahun 2012 perusahaan melakukan survey kepada 100 orang.Pelanggan yang puas terhadap pelayanan PPOB sebanyak 70 orang sedangkan tidak puas sebanyak 30 orang.Hal ini menunjukkan bahwa sistem PPOB belum memberikan kepuasan kepada pelanggan.Hal ini ditunjukkan bahwa kinerja PPOB belum maksimal dalam memberikan pelayanan kepada pelanggan dan masih banyak sistem yang tidak mengenal identitas pelanggan mengakibatkan pelanggan bingung untuk membayar tagihan gas.

PT Perusahaan Gas Negara selalu merespon setiap perubahan teknologi informasi yang terjadi dalam lingkungan perusahaan. Terciptanya teknologi komputer dan jaringan sistem komunikasi seperti telepon, facsimile, wireless, dan lain-lain,untuk mempercepat perkembangan teknologi informasi. Sebagai salah satu unit bisnis PT Perusahaan Gas Negara memanfaatkan dan menyiasati perkembangan teknologi informasi untuk kemajuan perusahaan, hal ini sangat penting walaupun bisa berdampak pada perubahan proses bisnis.

Pemanfaatan teknologi informasi sangat berperan dalam keberhasilan program PPOB ini.Karena salah satu syarat untuk kesuksesan program PPOB adalah adanya sarana komunikasi yang berbasis teknologi informasi.Adanya sebuah jaringan komunikasi yang menghubungkan dan menggabungkan beberapa titik komunikasi menjadi satu kesatuan yang mampu berinteraksi antara satu dengan lainnya.Perusahaan Gas Negara telahmemperpanjang dan memperluas ISO 2008.Dengan mengimplementasi ISO, berarti Perusahaan Gas Negara telah menjalankanprosedur yang diakui internasional. Dengan demikian, makaperusahaan akan mempunyai kredibilitas yang baik.Perusahaan Gas Negara sebelumnya juga telah satu dekade melaksanakan ISO,ke depan Perusahaan Gas Negara akan terus berbenah untuk dapat melaksanakanstandar atau prosedur lainnya sebagai upaya berkelanjutan perbaikansecara internal.

Seiring meningkatnya kebutuhan energi yang bersih dan terjangkau, Perusahaan Gas Negara akan terus menggunakan keahlian dan pengalamannya untuk mendapatkan sumber energi baru melalui pemanfaatan berbagai moda transportasi demi memenuhi kebutuhan jangka panjang konsumen. Perusahaan Gas Negara saat ini telah melakukan kerjasama dengan pihak bank untuk mempermudah pembayaran gas kepada pelanggan kecil dan rumah tangga.

Layanan ini dilakukan dengan Payment Point Online Banking (PPOB), meskipun pelanggan gas rumah tangga hanya memberikan kontribusi bagi pendapatan $1 \%$, tetapi mempunyai peran yang sangat penting dalam mengurangi pemakaian minyak tanah."Dengan layanan ini membuat bisnis semakin efisien. 
Dalam melaksanakan program PPOB ini bank didukung lebih dari 50 loket payment point yang tersebar pada area layanan pelanggan PGN.Bank memiliki komitmen kepada nasabah dan pelanggan khususnya untuk menyediakan jasa dan produk perbankan yang dapat memenuhi semua aspek kebutuhannya, seperti transaksi harian, kebutuhan keluarga, hiburan, liburan, pendidikan dan kebutuhan lainnya.

Dengan adanya dukungan dari bank diharapkan dapat terus semakin memperkuat pelayanan kepada pelanggan gas rumah tangga. Kerjasama dengan bank selama ini sudah terjalin dengan baik, melalui kerjasama yang baru ini ke depan hubungan kedua belah pihak akan terus meningkat. Layanan PPOB untuk para pelanggan gas rumah tangga dapat langsung membayar tagihan gas yang datanya langsung terhubung dengan sistem jaringan PGN. Dengan berjalannya Sistem Payment Point Online Banking (PPOB), beberapa proses bisnis yang selama ini berjalan dapat disederhanakan. Dalam proses pembayaran tagihan gas maka tidak ada lagi berkerjasama secara langsung dengan payment point konvensional, tetapi hanya bekerjasama dengan pihak bank.

System Payment Point Online Banking diciptakan sebagai penyempurnaan dari sistem untuk melayani piutang pelanggan.Dalam sistem PPOB ini peranan loket menjadi berkurang. Dengan adanya payment point Online Banking menjadikan bisnis terbuka yang bisa diselenggarakan oleh semua pihak dengan menjadi mitra bank.Selanjutnya pemanfaatan infrastruktur komunikasi dapat memberikan manfaat penghematan biaya bagi masyarakat dan Negara.

Dalam sistem Payment Point Online Banking seluruh pola bisnis diatur melalui kerjasama antara PGN dengan pihak bank. Selanjutnya semua fasilitas untuk melayani pembayaran tagihan gas sepenuhnya disediakan pihak bank.Untuk efisiensi dan keamanan, pihak bank bisa menggandeng switching company yang menyediakan jalur komunikasi dan gateway agar sistem perbankan bisa mengakses ke Database Piutang Pelanggan Unit Pelaksana Induk (DPP-UPI).

Sistem Payment Point Online Banking mengurangi keruwetan administrasi dan birokrasi PGN, sehingga unit pelaksana dapat focus ke core bussines-nya. Akan tetapi hal tersebut harus diimbangi dengan munculnya kegiatan baru di kantor distribusi yaitu kegiatan pengelolaan DPP-UPI. Untuk itu diperlukan SDM dan Organisasi dengan kualifikasi tertentu yang berbeda dengan SDM yang ada di unit pelaksana.

Bank bisa melakukan integrasi horizontal ke sisi hilir, yaitu menggandeng provider agar point of sales bisa online ke jaringan perbankan, dan juga integrasi horizontal ke sisi hulu, yaitu menggandeng switching provider agar jaringan perbankan bisa akses secara online ke DPP-UPI. Sebagai konsekuensi, kerjasama pengembang -an dan operasi dari sisi teknologi informasi lebih banyak dilakukan antara PGN sebagai biller dengan switching company karena pada praktiknya memang kedua pihak tersebut yang melakukan interface secara langsung.

\section{TINJAUAN PUSTAKA \\ Kinerja}

Menurut Wibowo (2007) kinerja berasal dari pengertian performance.Adapun pengertian performance sebagai hasil kerja atau prestasi kerja. Namun, sebenarnya kinerja mempunyai makna luas, tidak hanya hasil kerja, tetapi bagaimana proses pekerjaan berlangsung. Menurut Wibowo (2007), kinerja merupakan hasil pekerjaan yang mempunyai hubungan dengan tujuan strategis organisasi, kepuasan konsumen, dan memberikan kontribusi pada ekonomi. 


\section{Payment Point Online Banking (PPOB)}

Payment Point Online Banking (PPOB) adalah Satu kesatuan Sistem Hardware dan Sistem Software Aplikasi, Jaringan Komunikasi Data dan Rekonsiliasi Data sehingga dapat berfungsi sebagai media interaksi sistem pembayaran tagihan apapun secara online dengan pihak bank sebagai penyelenggara sekaligus penampung dana pelanggan untuk diteruskan kepada mitra kerjanya. Payment Point adalah tempat atau loket yang menerima pembayaran pelanggan yang dikelola oleh perorangan, atau badan usaha yang telah bermitra kerja dengan Collecting Agent.Collecting Agent (CA) adalah badan usaha atau lembaga lain yang telah menjalin kerjasama dengan pihak perbankan sebagai penyelenggara dan penampungan dana tagihan dari pelanggan.

\section{Tekhnologi Informasi}

Sistem Teknologi Informasi (Information Technology System) dapat diartikan sebagai sistem yang dapat menghasilkan informasi yang berguna, dimana dalam penerapannya menggunakan teknologi informasi (Hartono, 2003).Pada perkembangan selanjutnya, Sistem Teknologi Informasi dapat digunakan oleh perusahaan dalam berbagai hal, seperti efisiensi, efektivitas, peran komunikasi, kolaborasi, dan kompetensi (Hartono, 2003).

\section{Pelayanan}

Menurut Balaji (2002) menyatakan bahwa," Pelayanan adalah suatu tindakan atau unjuk kerja yang diberikan seseorang ke orang lain." Menurut Zeithaml dan Bitner dalam Yazid (2001) Pelayanan menyatakan bahwa, "Peran orang yang ada dalam hal penyajian jasa terdiri dari karyawan lini depan dan yang mendukungnya dibagian belakang, sangat penting bagi keberhasilan organisasi jasa.

\section{Kerangka Konseptual}

Kerangka konseptual merupakan alur dari gambaran permasalahan hingga harapan yang diinginkan pada penelitian. Melalui penelitian ini diharapkan akan diketahui Kinerja Payment Point Online Banking (Ppob),PPOB berpengaruh terhadap Mempermudah Pelayanan pelanggan pada PT Perusahaan Gas Negara. Dengan menggunakan analisis regresi linier berganda akan diketahui besar pengaruh dari masing-masing variabel, kemudian disusun rekomendasi sebagai solusi penyelesaian permasalahan.Maka dapat disusun sebuah kerangka konseptual dalam penelitian ini sebagai berikut:

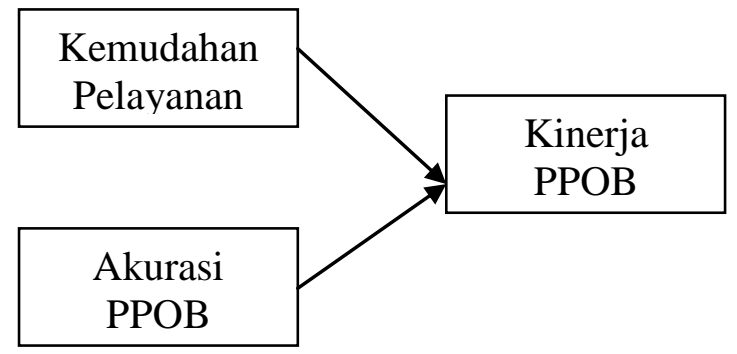

\section{Gambar 1 Kerangka Konseptual}

Dari permasalahan yang ada, dapat diambil suatu hipotesis simultan dan hipotesis parsial sebagai berikut : 
$\mathrm{H}_{1}$ : $\quad$ Kemudahan Pelayanan dan Akurasi PPOB diduga berpengaruh terhadap Kinerja Payment Point Online Banking (PPOB)pada pelanggan PT Perusahaan Gas Negara.

$\mathrm{H}_{2}$ : Kemudahan Pelayanan diduga berpengaruh terhadap Kinerja Payment Point Online Banking (PPOB)pada pelanggan PT Perusahaan Gas Negara.

$\mathrm{H}_{3}$ : Akurasi PPOB diduga berpengaruh terhadap Kinerja Payment Point Online Banking (PPOB)pada pelanggan PT Perusahaan Gas Negara.

\section{C.METODE PENELITIAN}

\section{Populasi dan Sampel}

Dalam penelitian ini populasi yang dimaksud adalah seluruh pelanggan rumah tangga yang menggunakan jasa Payment Point Online Banking (PPOB) pada PT Perusahaan Gas Negara.Dalam penelitian ini jumlah sampel yang digunakan adalah 120 orang. Kemudian untuk menentukan siapa yang akan dijadikan sampel dilakukan dengan metode accidental sampling yaitu pengambilan sampel dilakukan kepada pelanggan yang datang langsung membayar tagihan gas kepada kantor PT Perusahaan Gas Negara yang terdekat.

\section{Teknik Pengumpulan Data}

1. Pengamatan (observasi)

2. Wawancara

3. Kuisioner

\section{Metode Analisis Data}

Analisis regresi yang digunakan dalam penelitian ini adalah analisis regresi berganda (multiple regression analysis). Analisis regresi berganda adalah analisis hubungan antara dua atau lebih variabel bebas $(\mathrm{X})$ terhadap satu variabel terikat $(\mathrm{Y})$ dengan asumsi $\mathrm{Y}$ merupakan fungsi dari $\mathrm{X}$. Hasil analisis regresi adalah berupa koefisien untuk masing-masing variabel bebas.

Secara matematis, hubungan variabel tersebut dapat dinyatakan dalam bentuk sebagaiberikut:

$$
\mathbf{Y}=\mathbf{a}+\mathbf{b}_{1} \mathbf{X}_{1}+\mathbf{b}_{2} \mathbf{X}_{2}+\mathbf{e}
$$

Uji Hipotesis:
a. Uji Serempak (Uji F)
b. Uji Parsial (Uji t)
c. Koefisien Determinasi $\left(\mathrm{R}^{2}\right)$

\section{ANALISIS DAN PEMBAHASAN}

PT Perusahaan Gas Negaramerespon setiap perubahan teknologi informasi yang terjadi dalam lingkungan perusahaan. Hal ini dilakukan agar kinerja perusahaan dapat tercapai sesuai dengan target yang diinginkan. Terciptanya teknologi komputer dan jaringan sistem komunikasi seperti telepon, facsimile, wireless, dan lain-lain,untuk mempercepat perkembangan teknologi informasi. Sebagai salah satu unit bisnis PT Perusahaan Gas Negara memanfaatkan dan menyiasati perkembangan teknologi informasi untuk kemajuan perusahaan, hal ini sangat penting walaupun bisa berdampak pada perubahan proses bisnis. 
Dengan mengimplementasi ISO, berarti Perusahaan Gas Negara telah menjalankanprosedur yang diakui internasional. Dengan demikian, makaperusahaan akan mempunyai kredibilitas yang baik.Perusahaan Gas Negara sebelumnya juga telah satu dekade melaksanakan ISO,ke depan Perusahaan Gas Negara akan terus berbenah untuk dapat melaksanakanstandar atau prosedur lainnya sebagai upaya berkelanjutan perbaikansecara internal.

Perusahaan Gas Negara saat ini telah melakukan kerjasama dengan pihak bank untuk mempermudah pembayaran gas kepada pelanggan kecil dan rumah tangga.Layanan ini dilakukan dengan Payment Point Online Banking (PPOB), meskipun pelanggan gas rumah tangga hanya memberikan kontribusi bagi pendapatan $1 \%$, tetapi mempunyai peran yang sangat penting dalam mengurangi pemakaian minyak tanah."Dengan layanan ini membuat bisnis semakin efisien.

Dalam melaksanakan program PPOB ini bank didukung lebih dari 50 loket payment point yang tersebar pada area layanan pelanggan PGN.Bank memiliki komitmen kepada nasabah dan pelanggan khususnya untuk menyediakan jasa dan produk perbankan yang dapat memenuhi semua aspek kebutuhannya, seperti transaksi harian, kebutuhan keluarga, hiburan, liburan, pendidikan dan kebutuhan lainnya.

Analisis statistik Inferensial bertujuan untuk menguji data dan sampel yang ada sudah cukup kuat untuk menggambarkan populasinya dan mengukur derajat asosiasi antar variabel. Uji hipotesis dilakukan dengan analisis statistik inferensial dengan menggunakan analisis regresi berganda dalam menguji hubungan antara dua atau lebih variabel bebas $(\mathrm{X})$ terhadap satu variabel terikat $(\mathrm{Y})$.

\section{Model Regresi Linier Berganda}

\section{Tabel1}

Hasil Uji Koefisien Regresi

\begin{tabular}{|l|c|c|c|c|c|}
\hline \multirow{2}{*}{ Model } & \multicolumn{2}{|c|}{$\begin{array}{c}\text { Unstandardized } \\
\text { Coefficients }\end{array}$} & $\begin{array}{l}\text { Standardized } \\
\text { Coefficients }\end{array}$ & \multicolumn{2}{|l|}{} \\
\cline { 2 - 7 } & $\mathrm{B}$ & $\begin{array}{c}\text { Std. } \\
\text { Error }\end{array}$ & Beta & $\mathrm{t}$ & Sig. \\
\hline $\begin{array}{l}\text { (Constant) } \\
\text { Kemudahaan } \\
\text { Pelayanan }\end{array}$ & .984 & .597 & & 1.648 & .102 \\
\hline AkurasiPPOB & .203 & .036 & .373 & 5.163 & .000 \\
\hline
\end{tabular}

Sumber : Hasil Penelitian, 2014 (data diolah)

Berdasarkan Tabel 6.15 maka persamaan regresi linear berganda dalam penelitian ini adalah:

$$
Y=0,984+0,188 X_{1}+0,203 X_{2}
$$

1. Koefisien regresi $X_{1}$ untuk Kemudahan Pelayanan bernilai positif 0,162 artinya pengaruh kemudahaan pelayanan searah dengan Kinerja PPOB. Hal ini menunjukkan kemudahaan pelayanan memberikandampakpositif dalammeningkatkan kinerja PPOB.

2. Koefisien regresi $X_{2}$ untuk Akurasi PPOB bernilai positif 0,162 artinya pengaruh akurasi PPOB searah dengan Kinerja PPOB. Hal ini menunjukkan akurasi PPOB memberikandampakpositif dalammeningkatkan kinerja PPOB.

Berdasarkan pada Tabel 1 maka diperoleh hasil uji parsial sebagai berikut: 
1. Nilai $t_{\text {hitung }}$ untuk Kemudahan pelayanan 5,163 lebih besar dibandingkan dengan nilai $\mathrm{t}_{\text {tabel }} 1,65$ atau nilai sig $\mathrm{t}$ untuk Kemudahan pelayanan 0,000 lebih kecil dari alpha 0,05. Berdasarkan hasil yang diperoleh maka menolak $\mathrm{H}_{0}$ dan menerima $\mathrm{H}_{1}$ untuk Kemudahan pelayanan. Dengan demikian secara parsial Kemudahan pelayanan berpengaruh positif dan signifikan dalam meningkatkan kinerja PPOB, artinya Kemudahaan pelayanan akan memberikan pengaruh nyata dalam meningkatkan kinerja PPOB.

2. Nilai $t_{\text {hitung }}$ untuk Akurasi PPOB 5,083 lebih besar dibandingkan dengan nilai $t_{\text {tabel }}$ 1,65 atau nilai sig $t$ untuk Akurasi PPOB 0,000 lebih kecil dari alpha 0,05. Berdasarkan hasil yang diperoleh maka menolak $\mathrm{H}_{0}$ dan menerima $\mathrm{H}_{1}$ untuk Akurasi PPOB. Dengan demikian secara parsial Akurasi PPOB berpengaruh positif dan signifikan dalam meningkatkan kinerja PPOB, artinya Akurasi PPOB akan memberikan pengaruh nyata dalam meningkatkan kinerja PPOB. Hasil penelitian menunjukkan Akurasi PPOB yang dominan berpengaruh terhadap kinerja PPOB artinya Akurasi PPOB lebih menentukan dalam meningkatkan kinerja PPOB.

\section{Koefisien Determinasi $\left(\mathbf{R}^{2}\right)$}

Besarnya pengaruhvariabel bebas terhadap variabel terikat adalah denganmenggunakan uji koefisien determinasi $\left(\mathrm{R}^{2}\right)$ berikut :

\section{Tabel 2}

Hasil Uji Determinasi

\begin{tabular}{|c|c|c|c|c|}
\hline Model & $\mathrm{R}$ & R Square & $\begin{array}{c}\text { Adjusted R } \\
\text { Square }\end{array}$ & $\begin{array}{l}\text { Std. Error of the } \\
\text { Estimate }\end{array}$ \\
\hline 1 & $.919^{\mathrm{a}}$ & .845 & .841 & 1.03062 \\
\hline
\end{tabular}

Sumber : Hasil Penelitian, 2014 (data diolah)

Pada Tabel 2diperoleh nilai koefisien determinasi ( $R$ square) sebesar 0,845. Hal ini menunjukkan bahwa kemampuanKemudahan Pelayanan dan Akurasi PPOB dapat menjelaskan variasi dalam Kinerja PPOBsebesar 84,5\% dan sisanya sebesar $15,5 \%$ dipengaruhi oleh variabel-variabel lain di luar dari variabel yang diteliti.

\section{Uji F (Simultan)}

Tabel3

Hasil Uji F Simultan

\begin{tabular}{|ll|c|c|c|c|c|}
\hline & Model & $\begin{array}{c}\text { Sum of } \\
\text { Squares }\end{array}$ & df & $\begin{array}{c}\text { Mean } \\
\text { Square }\end{array}$ & F & Sig. \\
\hline 1 & Regression & 669.379 & 2 & 223.126 & 210.065 & $.000^{\mathrm{a}}$ \\
& Residual & 123.213 & 117 & 1.062 & & \\
Total & 792.592 & 120 & & & \\
\hline
\end{tabular}

Sumber : Hasil Penelitian, 2014 (data diolah)

Berdasarkan Tabel 3diperoleh hasil $\mathrm{F}_{\text {hitung }}$ sebesar160,426 sedangkan $\mathrm{F}_{\text {tabel }}$ pada $\alpha$ $=0,05$ dengan derajat pembilang 2 dan derajat penyebut 120 diperoleh $\mathrm{F}_{\text {tabel }}$ sebesar 2,13 maka dari hasil ini diketahui $F_{\text {hitung }}>F_{\text {tabel, }}$ dan signifikansi 0,000 atau lebih kecil 
dari $\alpha=0,05$ jadi posisi titik uji signifikansi berada pada wilayah penolakan $\mathrm{H}_{0}$. Dengan demikian dapat disimpulkan bahwa $\mathrm{H}_{1}$ diterima yang artinya Kemudahan pelayanan dan Akurasi PPOB secara bersama-sama berpengaruh positif dan signifikan terhadap Kinerja PPOB.Kemudahan pelayanan dan Akurasi PPOB secara bersama-sama menunjukkan adanya pengaruh positif sehingga berdampak dalam meningkatkan kinerja PPOB, sebaliknya jikaKemudahan pelayanan dan Akurasi PPOB secara bersama-sama tidak menunjukkan pengaruh positif maka akan berdampak pada penurunan kinerja PPOB.

\section{Pembahasan}

Hasil penelitian yang dilakukan secara simultan menunjukkan Kemudahan pelayanan dan Akurasi PPOB secara bersama-sama berpengaruh positif dan signifikan terhadap Kinerja PPOB pada pelanggan PT Perusahaan Gas Negara.Kemudahan pelayanan dan Akurasi PPOB secara bersama-sama menunjukkan adanya pengaruh positif sehingga berdampak dalam meningkatkan kinerja PPOB.

Hasil penelitian yang dilakukan secara parsial menunjukkan Kemudahan pelayanan berpengaruh positif dan signifikan dalam meningkatkan kinerja PPOB, artinya Kemudahaan pelayanan akan memberikan pengaruh nyata dalam meningkatkan kinerja PPOB. Akurasi PPOB berpengaruh positif dan signifikan dalam meningkatkan kinerja PPOB, artinya Akurasi $\mathrm{PPOB}$ akan memberikan pengaruh nyata dalam meningkatkan kinerja PPOB. Hasil penelitian menunjukkan Akurasi PPOB yang dominan berpengaruh terhadap kinerja PPOB artinya Akurasi PPOB lebih menentukan dalam meningkatkan kinerja PPOB pada pelanggan PT Perusahaan Gas Negara.

Nilai koefisien determinasi ( $R$ square) sebesar $84,5 \%$. Hal ini menunjukkan bahwa kemampuanKemudahan Pealayanan dan Akurasi PPOB dapat menjelaskan variasi dalam Kinerja PPOB cukup kuat sedangkan sisanya sebesar 15,5\% dipengaruhi oleh variabel-variabel lain di luar dari variabel yang diteliti.

PPOB (Payment Point Online Bank) adalah Satu kesatuan Sistem Hardware dan Sistem Software Aplikasi, Jaringan Komunikasi Data dan Rekonsiliasi Data sehingga dapat berfungsi sebagai media interaksi sistem pembayaran tagihansecara online dengan pihak bank sebagai penyelenggara. Sekaligus penampung dana pelanggan untuk diteruskan kepada mitra kerjanya. Payment Point adalah tempat atau loket yang menerima pembayaran pelanggan yang dikelola oleh perorangan, atau badan usaha.

PPOB merupakan layanan pembayaran secara online real time, yang diselenggarakan oleh pelaku usahadengan dunia perbankan, dan memanfaatkan fasilitas perbankan.Dengan demikian jelas bahwa telah terjadi adanya kesepakatan antara pihak pelaku usaha dengan pihak perbankan tentang pemanfaatan fasilitas perbankan dalam pembayaran konsumen bagi pelaku usaha. Dengan berjalannya PPOB, maka proses pembayaran tidak lagi bekerjasama dengan payment pont-payment point, tetapi hanya bekerjasama dengan pihak bank atau jasa keuangan lainnya. Tidak ada proses utang piutang dengan paymen point-payment point sebagaimana yang mungkin terjadi sebelumnya, yang ada adalah proses rekonsiliasi keuangan dengan bank atau jasa keuangan lainnya.

Hasil peneltian ini didukung penelitian terdahulu oleh Kunto Wibisono(2010) Hasil penelitian menunjukkan terdapat pengaruh yang signifikan terhadap aplikasi sistem teknologi informasi di perusahaan. Hasil ini mendukung hipotesis yang menyatakan bahwa "Penerapan teknologi informasi memberikan perbedaan yang signifikan ditinjau dari proses manajemen kualitas (strategic planning process, output 
quality assurance, important innovations, human resources utilization, information and analysis)".

\section{E. KESIMPULAN}

\section{Kesimpulan} berikut:

Berdasarkan hasil penelitian dan pembahasan maka dapat disimpulkan sebagai

1. Hasil penelitian menunjukkan bahwa kinerja Payment Point Online Banking $(P P O B)$ berpengaruh dalam mempermudah pelanggan dalam kegiatan PPOBpada PT Perusahaan Gas Negara. Hal ini didukung dari hasil penelitian yang menyatakan Kemudahan pelayanan dan Akurasi PPOB secara bersama-sama berpengaruh positif dan signifikan dalam meningkatkan kinerja PPOB pada pelanggan PT Perusahaan Gas Negara.

2. Hasil penelitian menunjukkan Kemudahan pelayanan secara parsial berpengaruh positif dan signifikan dalam meningkatkan kinerja PPOB, begitu juga dengan Akurasi PPOB berpengaruh positif dan signifikan dalam meningkatkan kinerja PPOB.

3. Nilai koefisien determinasi memberikan gambaran pada Kemudahan pelayanan dan Akurasi PPOBdalam menjelaskan variasi yang cukup kuat untuk meningkatkan kinerja PPOB pada pelanggan PT Perusahaan Gas Negara

\section{DAFTAR PUSTAKA}

Andi, Sunyoto. 2006. Sistem Pengolahan Basis Data MS-SQL Server + SQL, Yogyakarta: Penerbit Modul Andi Sunyoto, S.Kom.

Arikunto, S. 2005. ManajemenPenelitian. Jakarta: Rieka Cipta.

Ariani, D.W., 2004. Pengendalian Kualitas Statistik (Pendekatan Kuantitatif Dalam Manajemen Kualitas). Penerbit ANDI, Yogyakarta.

Arnia, M, 2001, Evaluasi Kinerja Organisasi Pemerintahan Kabupaten Siak Propinsi Jambi.Jurnal Pemda Siak No. 16 Edisi X, Agustus 2001.

Bastian, Indra. 2001, "Akuntansi SektorPublik",Yogyakarta: BPFE.

Balaji, B. 2002.Services Marketing and Management. New Delhi: Chand \& Company LTD.

Beal, R.M 2000. "Competing Effectively : Environment Scanning, Competitive Strategy \& Organization Performance in Small Manufacturing Firms". Journal of Small Business Management.

Berkley BJ, Gupta A. Improving service quality with information technology. International Journal of Information Management.April, No. 14:109-121.

Brennan L. 2001. Total quality management in a research and development environtment. MCB University Press: Integrated Manufacturing System.

Cooper, Donald R, and Schindler, Pamela S. 2003.Business Research Methods, $7^{\text {th }}$ Edition, Mc. Graw Hill, Irwin.

De, Waal. 2001. Tree of Origin: What Primate Behavior Can Tell Us about Human social Evolution, Harvard University Press.

Effendy, Onang Uchjana. 2002. Hubungan Masyarakat Study Komunikasi Bandung: P.T. Remaja Rosdakarya. 
Erich, Helfert, A, 1996, Teknik Analisis Keuangan (Petunjuk Praktis Untuk Mengelola dan Mengukur Kinerja Perusahaan), Edisi 8, Erlangga, Jakarta, 1996.

Ferdinand, Agusty T. 2006. Structural Equation Modeling dalam Penelitian Manajemen. Aplikasi Model-model Rumit Dalam PenelitianUntuk Tesis Magister dan Disertasi Doktor.Yogyakarta:Universitas Diponogoro.

Ghozali, Imam.2005.Statistik Non-Parametrik. Semarang: Badan Penerbit Universitas Diponegoro.

Ghozali, Imam. 2006. "Apliklasi Analisis Multivariate Dengan Program SPSS'. Semarang : Badan Penerbit Undip.

Handayaningrat, Soewarno. 1996. Administrasi Pemerintah Dalam Pembangunan Nasional.Jakarta: CV Haji Mas Agung.

Http://harsupandahliiman.blogspot.com/2013/01/pengenrtian-akurasi.html.

Hartono J. 2003. Sistem teknologi informasi pendekatan terintegrasi, konsep dasar teknologi, aplikasi, pengembangan, dan pengelolaan. Yogyakarta: Andi Offset.

Husein, Umar, 2005. Metode Penelitian. Jakarta : Salemba Empat.

Indriantoro, Supomo, 2002. Metodologi Penelitian Bisnis untuk Akuntansi dan Manajemen, Edisi Pertama, BPFE, Yogyakarta.

Juran JM. 1988. Juran's Quality Control. Mc. Graw Hill.

Karabakal N, Gunal A, Ritchie W. 1995. Supply chain optimization tools improve the vehicle distribution at Volkswagen of America. (working paper). PROMODEL Inc.

Kitab Undang-Undang HukumPerdata (BurgerlijkWetboek),Niniek Suparni, 2000. PT Rineka Cipta.

Kotler, K.L.Keller. 2009. Manajemen Pemasaran. Jakarta: Penerbit Erlangga.

Kuncoro, Mudrajad. 2004. Otonomi Dan Pembangunan Daerah: Reformasi, Perencanaan, Strategi, dan Peluang. Jakarta: Erlangga.

Lagrosen S. 2001. Strengthening the weakest link of TQM from customer focus to customer understanding. The TQM Magazine, Volume 13 Number 5:348-354.

Lupiyoadi, Rambat 2009.Manajemen Pemasaran Jasa, Jakarta: Salemba Empat.

Mas'ud, Fuad. 2004. Survai Diagnosis Organisasional Konsep \& Aplikasi. Badan Penerbit Universitas Dipenogero. Semarang

Mc Adam \& Jackson N. 2002.A sectoral industry of ISO 9000 and TQM transition: the $U K$ and Irish bresing sector. MCB University Press: Integrated Manufacturing System.

Murphy KJ. et al. 1996. Dietary flavanols and procyanidin oligomers from cocoa (Theobroma cacao) inhibit platelet function 1-3 Am J Clin Nutr (77): 14661473 .

Nasution. 2004. Manajemen Jasa Terpadu. Jakarta: Ghalia Indonesia.

Rangkuti, Freddy. 2002. Riset Pemasaran. Jakarta: Gramedia Pustaka Utama.

Sedarmayanti. 2001. Produktivitas Kerja Karyawan. Bandung: Mandar Maju

Sekaran, Uma. 2006. Metodologi Penelitian untuk Bisnis. Jilid 1.Edisi 4. Salemba Empat

Sinulingga, Sukaria. 2011, Metode Penelitian, USU Press, Medan

Sugiyono, 2006, Statistika Untuk Penelitian, Cetakan Ketujuh, Bandung: CV. Alfabeta.

Supranto, J. 2006, Pengukuran Tingkat Kepuasan Pelanggan untuk Menaikkan Pangsa

Pasar, Cetakan Ketiga PT. Rineka Cipta, Jakarta.

Tschohl, dan S Franzmeier. (terj). 2003. Achieving Excellent Through Costumer. 
Venkatraman dan Ramanujam. 1986. Measurement of BusinessPerformance in Strategy Research: A Comparison of Approaches,Academy of Management Review, Vol. 1 (4), 801-04.

Voss,G.B and Voss Z.G.,2000.Strategic Orientation and Firm Performance in an Artistic Environment.Journal of Marketing, Vol.64, (January), pp.67-83

Wibowo. 2007. Manajemen Kinerja :Rajawali Pers. Jakarta.

Yazid. 2001, Pemasaran Jasa : Konsep dan Implementasi, Edisi Kedua, Penerbit: Fakultas Ekonomi. UII, Yogyakarta

Zadrony MA, Ferrazzi KE. 1992. Building a technology base for TQM. Chief Information Officer Journal, Vol. 5 Nos. 